\title{
Central lymph node changes and progressive massive fibrosis in coalworkers
}

\author{
RME SEAL, A COCKCROFT, I KUNG, JC WAGNER \\ From the Pathology Department and Medical Research Council Pneumoconiosis Unit, Llandough Hospital, \\ Penarth, South Glamorgan
}

ABSTRACT Lungs from 123 coalworkers coming to necropsy were examined to determine the association between dust related changes in the central lymph nodes and progressive massive fibrosis and secondary foci in the lung parenchyma. Increasingly extensive changes of the central nodes were scored macroscopically, the highest scores indicating erosion through the walls of adjacent bronchi or branches of the pulmonary artery or both. In 88 cases (mainly with extensive changes) microscopic assessment was also made. Increasingly extensive changes of central nodes were associated with the presence of progressive massive fibrosis in the lungs $(p<0.001)$ and the presence of secondary foci in lungs without progressive massive fibrosis $(p<0.03)$. Microscopic assessments agreed fairly well with macroscopic assessments, but tended to be assigned lower scores. A hypothesis for the pathogenesis of progressive massive fibrosis is proposed whereby dust, accumulating in central lymph nodes, leads eventually to spread through the capsule and rupture into bronchi or pulmonary vessels, thereby sending dust laden activated cells back into the lungs to produce progressive massive fibrosis. These preliminary results are consistent with the hypothesis but more detailed studies are required.

The pathogenesis of progressive massive fibrosis in coalworkers' pneumoconiosis remains ill understood. The disease is more likely to occur in coalworkers who have had a heavy total dust exposure ${ }^{1}$ and is associated with high levels of dust in the lungs at necropsy. ${ }^{2}$ The stimulus for formation of progressive massive fibrosis in particular men is unknown, though probably various factors play a part. The theory that pulmonary tuberculous infection is the main cause ${ }^{3}$ now has to be abandoned. ${ }^{4}$ Quartz may be a factor in certain types of progressive massive fibrosis and there is an association between the rheumatoid diathesis and the 'Caplan' type of progressive massive fibrosis. ${ }^{5}$ But in many cases no obvious precipitating factor is present and it is not clear why progressive massive fibrosis occurs. The lymph nodes in coalworkers' pneumoconiosis have received little attention and there have been no studies of the relationship between

Address for reprint requests: $\operatorname{Dr}$ A Cockcroft, Department of Medicine, Charing Cross and Westminster Medical School, London W6 8RF.

Accepted 24 November 1985 lymph node changes and the range of parenchymal changes.

On many occasions we have noted heavily dusted lymph nodes breaching their capsules so that their contents extend through into pulmonary vessels or bronchi, or both, in cases where there is progressive massive fibrosis in areas of the lung served by the vessels or bronchi concerned. By analogy with caseous lymph nodes in primary tuberculosis, when rupture into bronchi is associated with a hypersensitivity pneumonitis of the distal lung (so called epituberculosis), the changes in central structures in coalworkers' lungs may well have a vital role in the chain of events leading to progressive massive fibrosis. Wells $^{6}$ reported that the pneumoconiotic process could affect and cause ulceration of the wall of large and medium sized pulmonary arterioles but did not discuss the possible significance of this in the pathogenesis of progressive massive fibrosis.

The opportunity to investigate the association between central node dust changes and progressive massive fibrosis arose during a survey of postmortem lung pathology in a group of South Wales coalworkers. ${ }^{78}$ We were able to examine the central nodes and compare the findings with features in the lung parenchyma. 

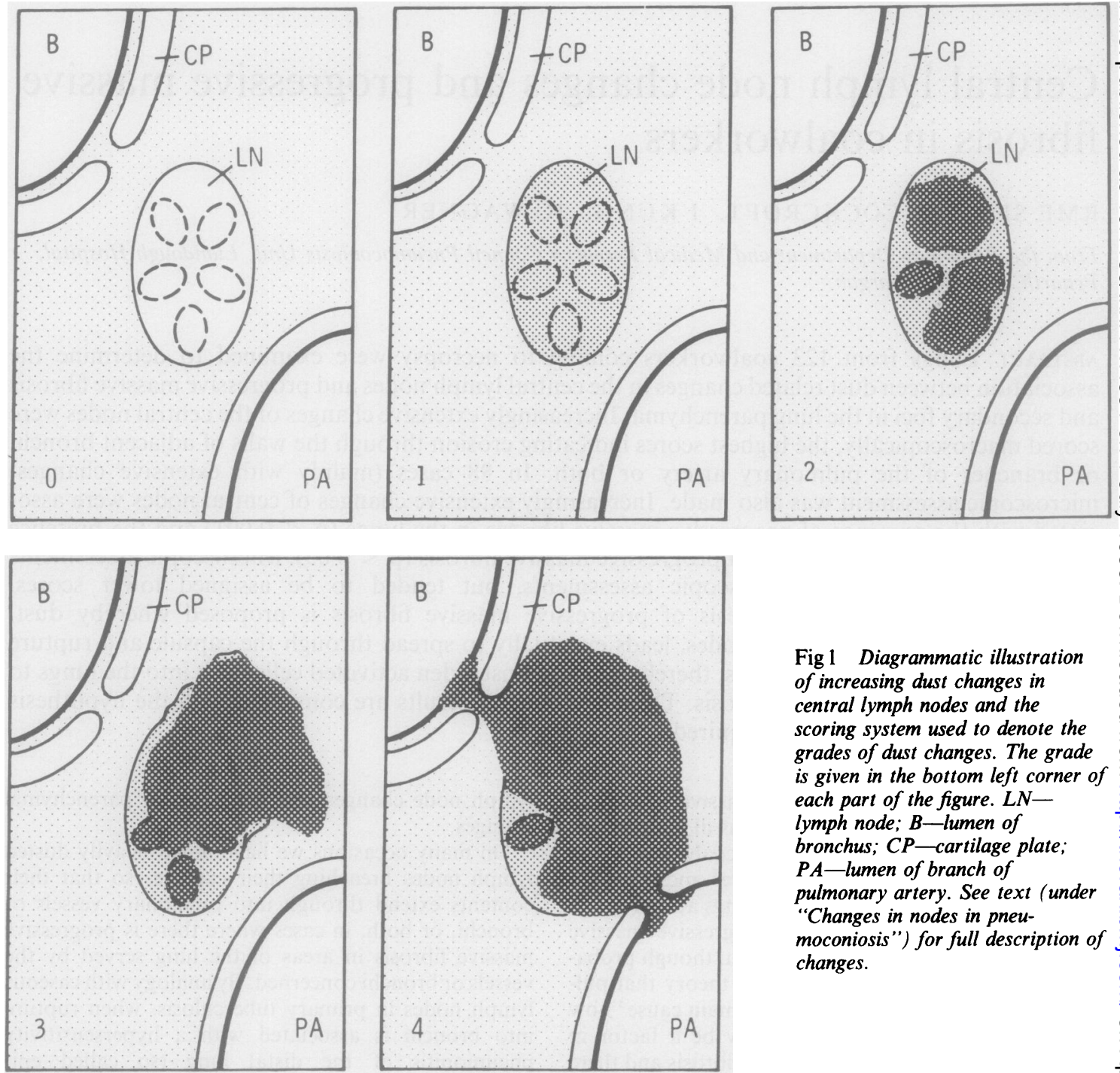

Fig 1 Diagrammatic illustration of increasing dust changes in central lymph nodes and the scoring system used to denote the grades of dust changes. The grade is given in the bottom left corner of each part of the figure. $L N$ lymph node; $B$-lumen of bronchus; $C P$-cartilage plate; $P A$-lumen of branch of pulmonary artery. See text (under "Changes in nodes in pneumoconiosis") for full description of changes.

\section{Methods}

We studied fixed inflated lungs from 123 consecutive postmortem examinations on coalworkers in Mid and South Glamorgan. They were forwarded from the Cardiff Pneumoconiosis Medical Panel before the panel's own routine examination. For a short period lungs of all coalworkers received by the panel were sent, but thereafter only the lungs of men who had spent at least 10 years underground. The lungs in the study were all those collected during about a year.

The lungs were sliced in a sagittal plane to include both upper and lower lobes. Parenchymal features were studied on this single cut surface. Dust foci were divided into two types: soft, peribronchiolar primary dust foci, which are the basic lesions of coalworkers' pneumoconiosis; and larger, palpable secondary dust foci. The secondary foci were classified as either stellate or circumscribed and the number of each type was noted. Progressive massive fibrosis was defined as any dust lesion more than $2 \mathrm{~cm}$ in diameter. The total diameter of all progressive massive fibrosis lesions on the cut surface of the lung was noted.

The hilum of the lung was examined macroscopically in every case to assess the state of the lymph nodes and their relationship to other central struc- 
Table 1 Central node changes in relation to the presence of secondary dust foci and progressive massive fibrosis in the lungs

\begin{tabular}{|c|c|c|c|c|c|}
\hline & \multicolumn{5}{|c|}{ Grade of central node changes } \\
\hline & $\overline{0}$ & 1 & 2 & 3 & 4 \\
\hline $\begin{array}{l}\text { Progressive massive fibrosis in lungs } \\
\text { None } \\
<5 \mathrm{~cm} \text { diameter } \\
\geqslant 5 \mathrm{~cm} \text { diameter } \\
\text { Stellate secondary foci* }\end{array}$ & 5 & 23 & 10 & $\begin{array}{r}13 \\
5\end{array}$ & $\begin{array}{l}25 \\
14 \\
28\end{array}$ \\
\hline $\begin{array}{l}\text { None } \\
1-9 \\
\geqslant 10 \\
\text { Circumscribed secondary foci }\end{array}$ & 5 & $\begin{array}{r}21 \\
1 \\
1\end{array}$ & $\begin{array}{l}8 \\
2\end{array}$ & 13 & $\begin{array}{l}12 \\
12\end{array}$ \\
\hline $\begin{array}{l}\text { None } \\
1-9 \\
\geqslant 10\end{array}$ & 5 & 23 & 10 & $\begin{array}{r}12 \\
1\end{array}$ & $\begin{array}{r}20 \\
3 \\
1\end{array}$ \\
\hline
\end{tabular}

*In lungs without progressive massive fibrosis. In a few lungs both types of secondary foci were present.

tures. Macroscopic dust changes in the nodes were described according to the scoring system illustrated in figure 1 . Grade 4 in figure 1 was additionally divided into $4 \mathrm{~b}$ (bronchus breached), $4 \mathrm{p}$ (branch of pulmonary artery breached), and $4 \mathrm{bp}$ (both breached). Where there was variation in the degree of lymph node changes in an individual, the score was assigned to the most heavily affected nodes. In cases where the nodes macroscopically were heavily laden with dust, and in a few cases apparently little affected, sections were taken and prepared for histological examination. Bronchi and vessels were examined on a limited number of slices and were not opened along their length to look for dust on the inner surface.

Microscopic assessments were made by IK, who is a general pathologist and was not otherwise concerned in the study and who was unaware of the findings in the lung parenchyma. He used the same scoring system as in figure 1 . Sections of central nodes were examined in 88 cases; nine of these were discarded as unsatisfactory for assessment, leaving 79 assessments for comparison with macroscopic findings.

The significance of associations between scores for different pathological features was tested with the Mantel extension of the Mantel-Haenszel $\chi^{2}$ test. $^{9}$

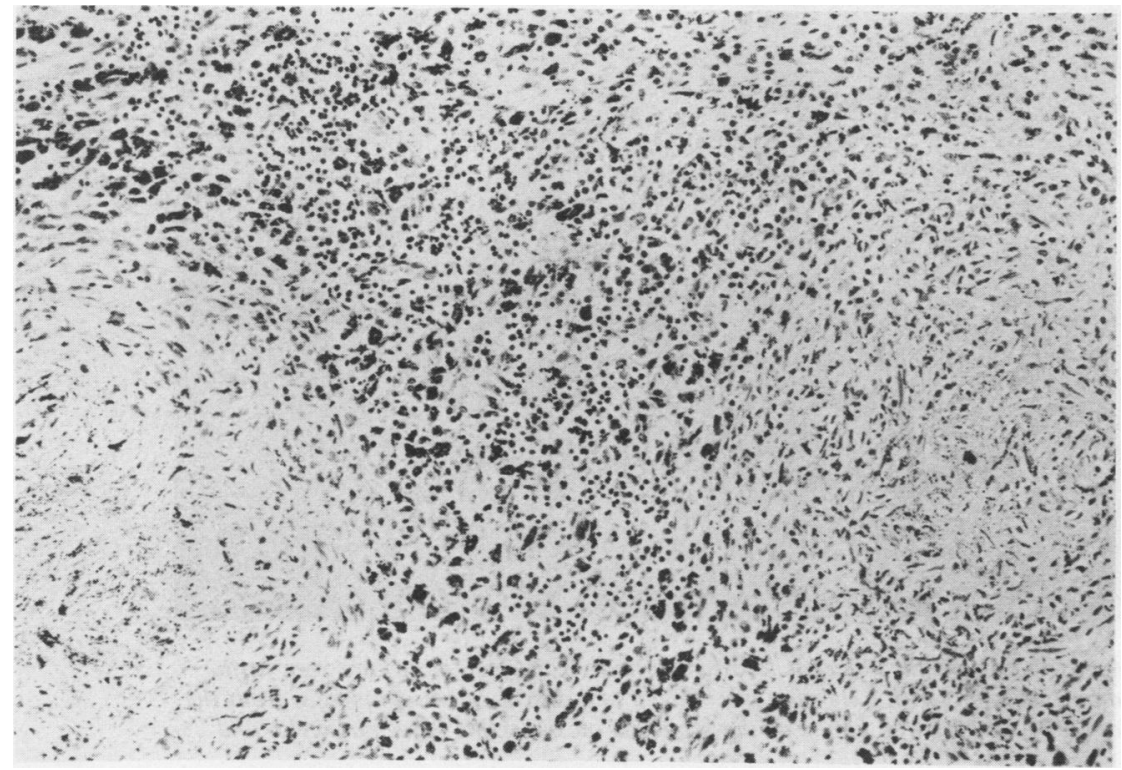

Fig 2 Lymph node with two foci of necrosis in the medulla, the one on the right also showing fibroblastic proliferation. (Haematoxylin and eosin.) 


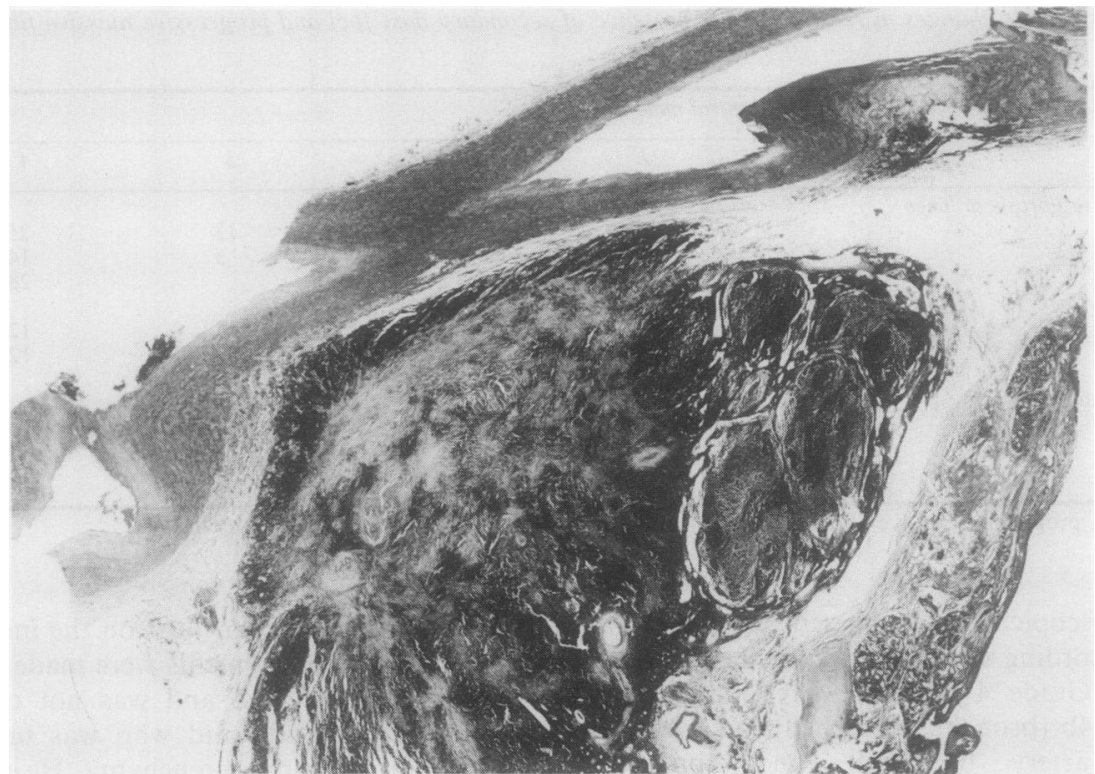

Fig 3 Lymph node showing normal lymphoid follicles on the right, adjacent to the lumen of a bronchus, with the capsule intact. On the top left the infiltrative process has breached the capsule and extended towards but not affected a pulmonary artery. Note the rectangular distortion of the node outline. (Haematoxylin and eosin.)

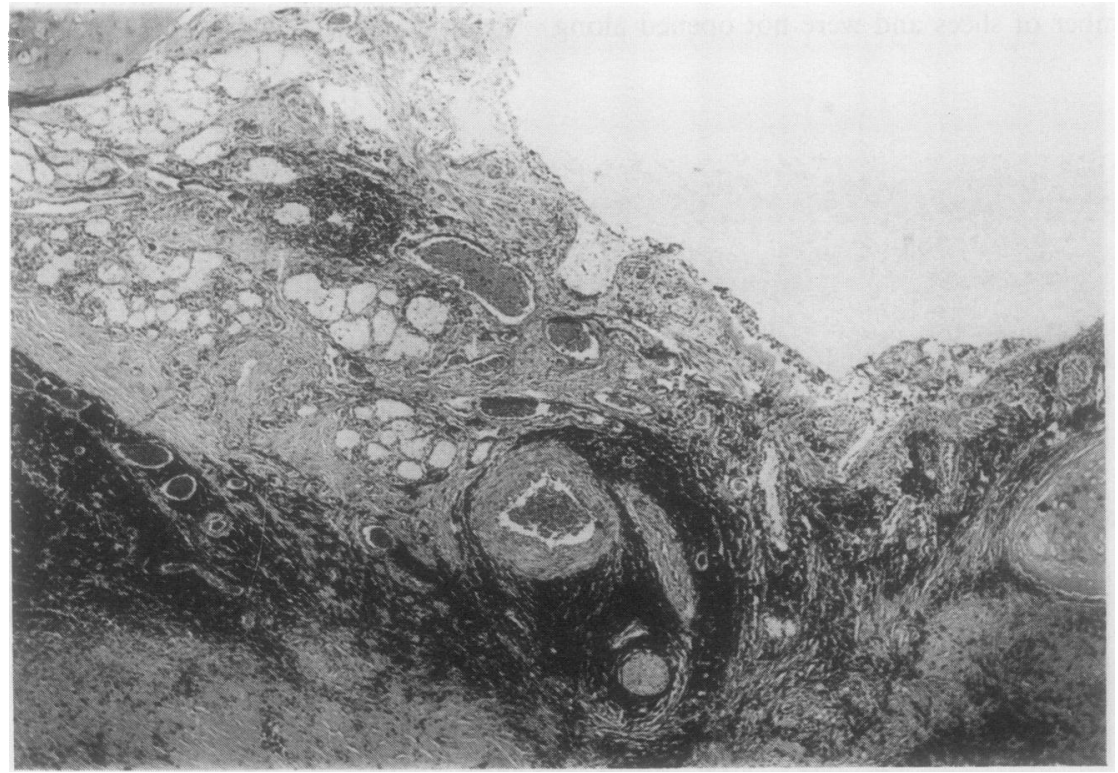

Fig 4 Changes in a bronchus adjacent to a lymph node. Cartilage plates are seen at the top left and bottom right, with extension of collagen and dust laden macrophages from the node (bottom left) towards the lumen of the bronchus on the right. (Haematoxylin and eosin.) 


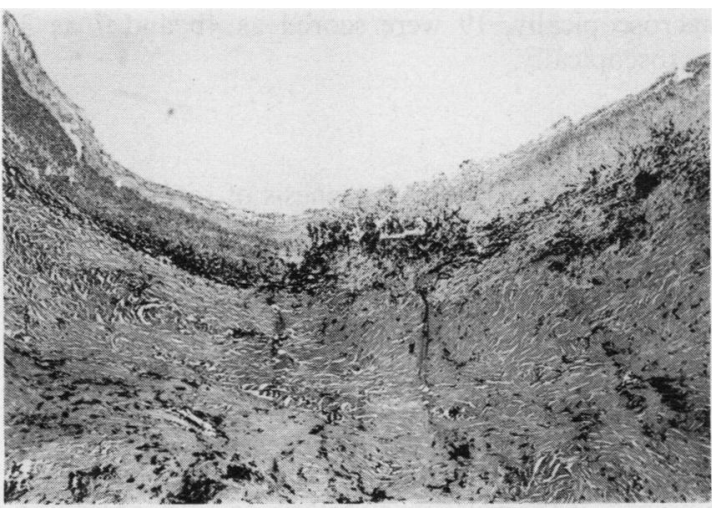

Fig 5 Collagenous and macrophage encroachment on an arterial wall. The material from the node forms part of the vessel wall (centre). (Haematoxylin and eosin.)

\section{Results}

MACROSCOPIC ASSESSMENT OF CENTRAL NODES In $69 \%$ of the lungs the central nodes were thought to have breached their capsules at some point (grade 3 or 4) and in 54\% there was dust penetration of a bronchus, a pulmonary vessel, or both (variants of grade 4). Dust was more common in bronchi than in pulmonary vessels and pulmonary vessels alone were rarely affected. Macroscopic appearances of affected nodes are shown in figure 6 . Figure 7 , from a paper mounted section of a whole lung, shows node and parenchymal changes.

There was an association between central node changes and progressive massive fibrosis in the lung (table 1). In all lungs where progressive massive

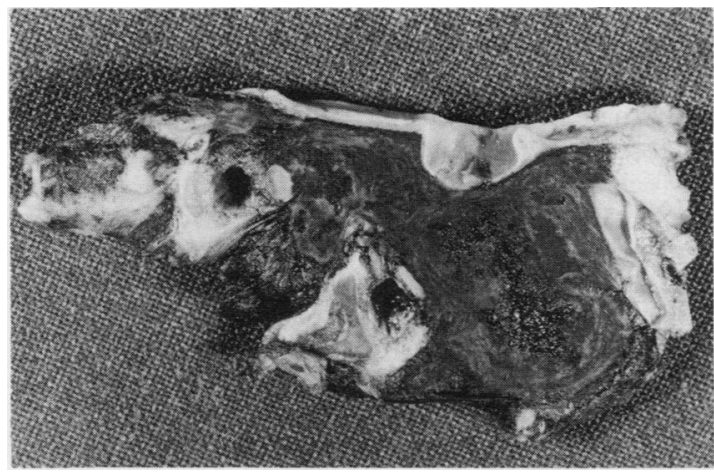

Fig 6 Macroscopic specimen of a node lesion affecting both a bronchus and a vessel. The node is irregular in shape and has extended beyond its capsule between cartilage plates of a bronchus (bottom centre) and into the wall of a branch of the pulmonary artery (top left). Note the black intimal surface of the artery. fibrosis more than $5 \mathrm{~cm}$ in diameter was present the central nodes were graded 4. Even smaller areas of progressive massive fibrosis were confined to lungs with nodes having dust changes of grade 3 or more. The association between increasing central node changes and the presence of progressive massive fibrosis in the lungs was significant at the $0.1 \%$ level $\left(\chi^{2}=37.22\right)$ - see table 1 .

The associations between increasing score for changes in the central nodes and the presence of secondary dust foci were examined in lungs without progressive massive fibrosis. The association with stellate foci was significant at the $0.1 \%$ level $\left(\chi^{2}=10.67\right)$ and the association with circumscribed secondary foci at the $3 \%$ level $\left(\chi^{2}=5.70\right)$ - see table 1 . In four lungs containing stellate secondary foci the nodes were graded 1 or 2 , but all lungs with circumscribed secondary foci had grade 3 or 4 central nodes.

\section{MICROSCOPIC FEATURES OF CENTRAL NODES \\ Changes in nodes in pneumoconiosis}

The following description is a reconstructed sequence of events that seem to us likely, on the basis of an examination of many lungs. Naturally, there has not been any longitudinal study in individuals. The factors that enhance or inhibit the process are unknown. Figure 1 is a diagramatic illustration of this sequence of increasing changes in nodes, with gradings that were used for both macroscopic and microscopic assessments of the nodes in this study.

The earliest change, seen in young miners with only simple pneumoconiosis, is packing of the medulla of the node with macrophages laden with coal dust, the dust particles having arrived from the pulmonary parenchyma. In nodes heavily laden with dust two events seem to occur: the appearance of small focal areas of necrosis of the macrophages and the appearance of fibroblasts with deposition of collagen (fig 2). Necrosis and fibrosis continue until the node is more or less completely replaced; either process may predominate. The next stage in hilar node lesions is when the necrosis and fibrosis within the node breaches the capsule. The necrotic collagenous area extends, preceded by a mantel of dust laden macrophages (fig 3). As the available "space" between the node and nearby bronchi and vessels is filled the node appears enlarged and irregularly shaped in cross section. Finally, the migrating macrophages, followed by the necrotic and sclerotic material may extend between the cartilagenous plates of the walls of large central bronchi and erode the epithelial surface (see fig 4). The ciliated respiratory epithelium may become replaced by cuboidal epithelium and there is loss of submucosal structures. The pulmonary arteries may also be invaded, with areas in their walls where all muscular and elastic tissues have disappeared and where many 


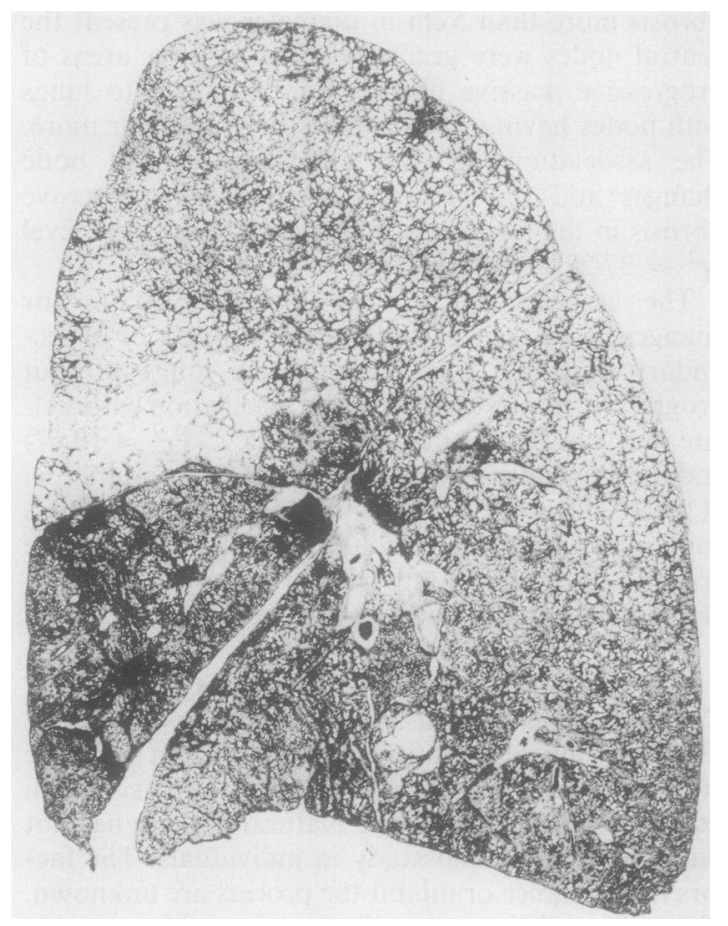

Fig 7 Paper mounted section of a whole lung showing progressive massive fibrosis and secondary foci in a segment of lung with heavily dust laden central nodes, but with the remainder of the lung showing only mild simple pneumoconiosis.

dust laden macrophages can be seen on the intimal surface (see fig 5). Often both bronchi and vessels are breached in the same lung (fig 6).

Microscopic assessment of nodes in the study There was quite good agreement between macroscopic and microscopic assessments (table 2). Thirty six cases were assigned lower scores microscopically than macroscopically, whereas only six cases had higher microscopic scores. Of $\mathbf{4 0}$ cases scored as $\mathbf{4 b p}$ macroscopically, 19 were scored as $4 \mathrm{~b}$ and 7 as 3 microscopically.

\section{Discussion}

A hypothesis for the pathogenesis of secondary dust foci and progressive massive fibrosis in coalworkers' pneumoconiosis could be framed as follows. Dust, ${ }^{\infty}$ initially accumulating in primary foci around terminal $\vec{\circ}$ bronchioles, is removed continuously by macro- $\vec{\overrightarrow{ }}$ phages to intersegmental and hilar lymph nodes, $\stackrel{\omega}{\circ}$ where it accumulates. Dust induced reactions in these $\vec{F}$ nodes lead eventually to rupture of the capsule. This is frequently accompanied by rupture into a bronchus, a branch of the pulmonary artery, or both, spreading iv dust laden activated cells back into a lung segment. $\omega_{-}$ There they produce secondary foci and progressive 을 massive fibrosis.

This study provides initial support for this hypoth- $\vec{c}$ esis in that lungs with progressive massive fibrosis and secondary dust foci had central nodes heavily laden $\vec{\bullet}$ with dust. The association between large areas of $\infty$ progressive massive fibrosis and lesions of the central nodes could arise as a result of direct extension of the lesions into the nodes, but this is not likely to be the case with the smaller lesions of progressive massive $\overline{0}$ fibrosis or secondary dust foci. Other possible explanations for the association between lesions of central $\unrhd$ nodes and progressive massive fibrosis would include $\overrightarrow{\overrightarrow{0}}$ impairment of bronchial clearance by the nodes or 3 failure of the nodes to function in lymphatic clearance from the lung.

Nodes heavily laden with dust were present in many lungs without progressive massive fibrosis or second- 을 ary foci, but progressive massive fibrosis was not $\stackrel{x}{x}$ found without grade 3 or 4 changes of the nodes. This implies that the central node changes precede the secondary foci and progressive massive fibrosis in the $O$ lung parenchyma. There was no evidence in this small study that the men with heavily dust laden nodes, in 윽 the absence of progressive massive fibrosis or second- $\rightarrow$ ary foci, differed in age at death from men with less affected nodes, or from men with heavily dust laden $\tilde{N}$

Table 2 Comparison of macroscopic and microscopic assessments of dust involvement of central nodes

\begin{tabular}{|c|c|c|c|c|c|c|c|}
\hline & & \multicolumn{6}{|c|}{ Grade* on microscopic assessment } \\
\hline & & $I$ & 2 & 3 & $4 b$ & $4 p$ & $4 b p$ \\
\hline $\begin{array}{l}\text { Grade* on } \\
\text { macroscopic } \\
\text { assessment }\end{array}$ & $\begin{array}{l}1 \\
2 \\
3 \\
4 b \\
4 p \\
4 b p\end{array}$ & $\begin{array}{l}2 \\
1\end{array}$ & $\begin{array}{l}1 \\
2\end{array}$ & $\begin{array}{r}2 \\
1 \\
10 \\
5 \\
2 \\
7\end{array}$ & $\begin{array}{r}1 \\
10 \\
19\end{array}$ & & $\begin{array}{r}1 \\
1 \\
14\end{array}$ \\
\hline
\end{tabular}

See under "Methods" for definitions of grades $4 \mathrm{~b}, 4 \mathrm{p}$ and $4 \mathrm{bp}$. The ordering of these grades in the table is not intended to imply that they represent increasing changes of the nodes. 
nodes and progressive massive fibrosis. Among men without progressive massive fibrosis or secondary foci, length of underground exposure tended to be longer in those having nodes more heavily laden with dust $\left(\chi^{2}=2.8, p<0.10\right)$. The dust load itself does not seem to be the only factor in formation of progressive massive fibrosis. Occasionally an area of fibrosis is found in an otherwise lightly dusted lung but with the nodes to the segment containing the fibrotic lesion showing considerable dust changes. An example of this is shown in figure 7. The case in this figure was not part of the main study.

Unfortunately, in this study it was not possible to make macroscopic assessments of the central nodes in ignorance of the parenchymal findings, although the nodes were always assessed before a formal assessment of the parenchyma. The agreement with microscopic findings (made without knowledge of any other findings) tends to validate the macroscopic findings. The tendency for lower microscopic assessments could be due either to overassessment macroscopically or to the difficulties of including the relevant pathological changes in the sections without including a large number of blocks. In nine cases no artery was present on the sections examined.

The results of this preliminary study are consistent with a "central" hypothesis for the pathogenesis of progressive massive fibrosis in which, in some ill understood way, immunological reactions in the central nodes play a part. There is evidence that progressive massive fibrosis lesions themselves contain immunologically active material. ${ }^{1011}$ Further work on the associations between central node changes and lesions in the lung parenchyma is now planned, as well as more detailed studies of the affected nodes.
We thank the mortuary technicians of Llandough Hospital for their cooperation, Mr W Sullivan and his staff for the preparation of pathological material, Dr JP Lyons for arranging for lungs to be sent from the Pneumoconiosis Medical Panel, and Mr D Llewellyn for photography.

\section{References}

1 Jacobsen M, Rae S, Walton WH, Rogan JM. The relation between pneumoconiosis and dust exposure in British coalmines. In: Walton WH, ed. Inhaled particles III. Old Woking: Unwin Bros, 1971:903-17.

2 King EJ, Maguire BA, Nagelschmidt G. Further studies of dust in the lungs of coal miners. $\mathrm{Br} J$ Ind Med 1956;13:9-23.

3 Mann KJ. A radiological study of the relationship between tuberculosis and pneumokoniosis in coal miners. Thorax 1951;6:43-55.

4 Cochrane $\mathrm{AL}$. The attack rate of progressive massive fibrosis. Br J Ind Med 1962;19:52-64.

5 Caplan A. Certain unusual radiological appearances in the chest of coal miners suffering from rheumatoid arthritis. Thorax 1953;8:29-37.

6 Wells AL. Pulmonary vascular changes in coalworkers' pneumoconiosis. J Pathol Bacteriol 1954;68:573-87.

7 Cockcroft A, Seal RME, Wagner JC, Lyons JP, Ryder R, Andersson N. Post-mortem study of emphysema in coalworkers and non-coalworkers. Lancet 1982;ii:600-3.

8 Cockcroft A. The importance of irregular opacities on the chest radiograph of coalworkers. MD thesis, London University, 1985.

9 Mantel N. Chi-square tests with one degree of freedom: extensions of the Mantel-Haenszel procedure. $\mathrm{J} \mathrm{Am}$ Statist Ass 1963;58:690-700.

10 Wagner JC, McCormick JN. Immunological investigations of coalworkers' pneumoconiosis. $J \boldsymbol{R}$ Coll Physicians Lond 1967;2:49-56.

11 Wagner JC, Wusterman FS, Edwards JH, Hill RJ. Composition of massive lesions in coalworkers. Thorax 1975;30:382-8. 